\title{
Correlates Between Sleep Schedules, Mood and College Performance of Students in Online Education During Lockdown
}

\author{
Tanishka Pundhir ${ }^{1 *}$
}

\section{ABSTRACT}

The current research targeted to establish significant correlations between sleep schedules, mood and college performance of undergraduate students in online college during the pandemic situation. 130 undergraduate students (males and females) between ages of 17 to 21 years from universities across Delhi filled an online survey and the resulting data was subjected to analysis that gave correlations between our three variables. Significantly positive correlations were found between sleep schedules $(\mathrm{x}), \operatorname{mood}(\mathrm{y})$ and college performance $(\mathrm{z})$. $(\mathrm{rxy}=+0.538, \mathrm{rxz}=+0.562$, ryz $=+0.744$, each significant at $\mathrm{p}<0.5)$. These significant positive correlations implied that students having better sleep experienced better mood and college performance, along, better mood leading to a good college performance for undergraduate students and vice versa.

\section{Keywords: Spirituality, Gratitude, Demographic Variables, Students}

s I write this, it is 3 in the morning and my new online semester begins at 8 . This
should explain my curiosity for this particular research. When the world shut down
in 2020 because of the COVID-19 outbreak, our screens ended up becoming our lives, constricting the college life of young students down to their room. Amongst college students, the inability to recognize and address mental health challenges of students during pandemic could lead to long term consequences on their mental health and education. (Browning et al., 2021) Keeping this in mind, the mental health of college students must be monitored. A high percentage of students are found to be suffering from anxiety in the after effects of the pandemic. (Cao et al., 2020) Another thing affected in this online shift of the world was disturbance in sleep schedules. The term 'revenge bedtime procrastination' started to gain popularity recently. It happens when people try to complete leisure activities that they couldn't during their daytime such as binge watching- by staying awake till late nights or early mornings. (Kroese et al., 2014) In a longitudinal study, it was noted that with the beginning of lockdown and its gradual progression the sleep schedules of children were disturbed and quality of sleep decreased, which stabilized later on but wasn't as satisfactory as the initial phase. (Dellagiulia et al., 2020) A delay in bed-time and wake-up time along with poorer sleep quality was also found among college students during the lockdown situation. In the same research one third of the sample was found to have depressive and

${ }^{1}$ Student, Dept. Of Psychology, Bharati College, Delhi University, Delhi, India

*Corresponding Author

Received: August 17, 2021; Revision Received: September 20, 2021; Accepted: September 30, 2021

(C) 2021, Pundhir T.; licensee IJIP. This is an Open Access Research distributed under the terms of the Creative Commons Attribution License (www.creativecommons.org/licenses/by/2.0), which permits unrestricted use, distribution, and reproduction in any Medium, provided the original work is properly cited. 


\section{Correlates Between Sleep Schedules, Mood and College Performance of Students in Online Education During Lockdown}

anxiety symptoms. (Marelli et al., 2020) As much as the online shift is a blessing for us, the lockdowns that lead us to this world shift have an impact on various psychological aspects and sleep schedules of the young college students. A decrease in overall mood was noted amongst adults during the period of lockdown. (Gismero-González et al., 2020) The disturbed sleep patterns and its impacts on their mood and college performance through this phase of online education remains as the main objective of the current research.

\section{METHODOLOGY}

\section{Participants}

A total of 130 under-graduate students from universities across Delhi were participants of the research. The participants were between the ages of 17-21 years old. Out of the sample of these 130 participants, there were 77 male participants and 53 female participants.

Gender

130 responses

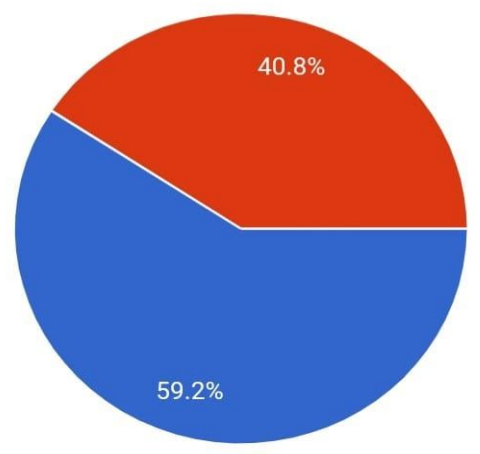

Figure 1. Percentage of male and female participants

Age

130 responses

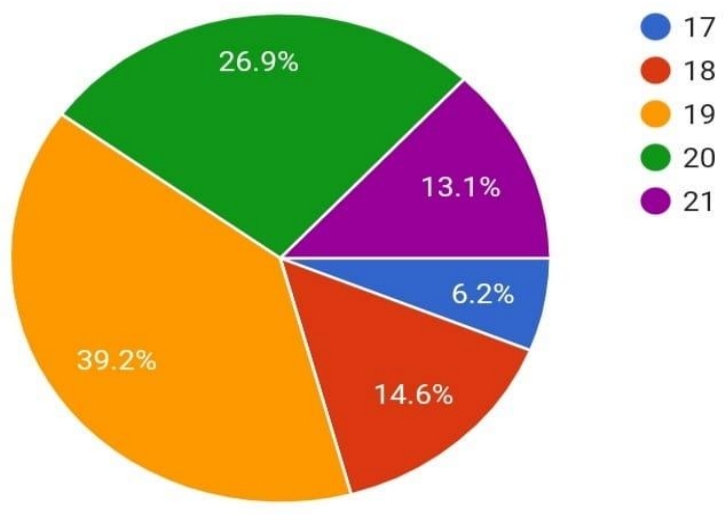

Figure 2. Participants by age in percentage

(C) The International Journal of Indian Psychology, ISSN 2348-5396 (e)| ISSN: 2349-3429 (p) | 2212 


\section{Correlates Between Sleep Schedules, Mood and College Performance of Students in Online Education During Lockdown}

\section{Sampling}

For the current research convenience sampling technique, which is a non-probability sampling method. This technique is also known as accidental sampling, where participants are chosen at the ease of accessibility. Thus, participants that were easy to reach-out to were taken up as the research sample with their full consent. (Etikan \& Bala, 2017)

\section{Research Design}

This research aimed to study the impact on mood and college performance of students as a result of bedtime procrastination and changed sleep schedules in times of online education due to Covid-19. A qualitative approach was followed for this study. For this purpose a survey containing 24 items with each item of the survey was to be responded on a 5 point scale (i.e. Strongly agree, Agree, Neutral, Disagree and Strongly disagree). The survey was developed and spread across online. The responses were collected from 130 voluntary under-graduate college students. Further, the responses were interpreted by establishing correlations between our three variables; sleep schedule, mood and college performance and understanding the association between the three.

\section{Procedure}

Measures employed in this research include a survey containing 24 items covering the three dimensions of sleep schedules, mood and college performance of 130 undergraduate students. The survey was spread across online and the participation was completely voluntary. After the collection of all responses, they were subjected to interpretation by establishing correlations amongst our three variables of sleep schedule, mood and college performance. Lastly, the correlations were analysed to show the associations amongst these three above mentioned variables.

\section{RESULTS}

As the study aimed to find an association between our three variables- sleep schedules(x), $\operatorname{mood}(\mathrm{y})$ and college performance $(\mathrm{z})$ of under-graduate students, a correlation was found between the three.

Table 1. Correlation matrix of the three variables

\begin{tabular}{|l|l|l|l|}
\hline & Sleep Schedules(x) & $\operatorname{Mood}(\mathbf{y})$ & College Performance(z) \\
\hline Sleep Schedules(x) & 1 & - & - \\
\hline Mood(y) & $+0.538^{*}$ & 1 & - \\
\hline College Performance(z) & $+0.562^{*}$ & $+0.744^{*}$ & 1 \\
\hline
\end{tabular}

* - implies the correlation is significant at $p<0.5$

Results have yielded significantly positive correlations between the three variables of the study. The correlation coefficient of sleep schedules and mood is $+0.538\left(r_{x y}=+0.538\right)$, a moderately positive correlation. Correlation coefficient of sleep schedules and college performance is $+0.562\left(\mathrm{r}_{\mathrm{xz}}=+0.562\right)$, again a moderately positive correlation. Lastly, the correlation coefficient between mood and college performance of students is $+0.744\left(\mathrm{r}_{\mathrm{yz}}=\right.$ $+0.744)$, a high positive correlation. 


\section{Correlates Between Sleep Schedules, Mood and College Performance of Students in Online Education During Lockdown}

\section{DISCUSSION}

With this study we established significant positive correlation between our three variables; sleep schedules, mood and college performance of under-graduate students during the lockdown period and phase of online education. The correlation coefficient between sleep schedules and mood was +0.538 , a moderate positive correlation, implying that with better sleep schedules students observe better moods and vice versa. In research related to medical students, it was found that disturbed sleep patterns were associated with mood disturbance and bad performance. (Singh et. al., 2009) This corroborates with our correlation between sleep and college performance, which was +0.562 , a moderately positive correlation, implying that better sleep schedules can yield better college performances and vice versa. A large research study found that people with better sleep reported feeling less exhausted, having a healthy Body Mass Index (BMI) and good academic performance. (Becker et. al., 2008) A study done on 172 undergraduate students also observed that college students often develop a problem of having delayed sleep and that there remains some significant association between good sleep and success in academic performance. (Chiang et. al., 2014) Finally, the correlation between mood and college performance was found to be a highly positive correlation with correlation coefficient being +0.744 which means that the better moods of a student significantly led to them giving a better college performance which includes their submissions, attendance, assignments and attentiveness in online classrooms. Another research found that students having moderate levels of depressive symptoms had lower academic performance in comparison to those with normal and minimal levels of depression. (DeRoma, Leach \& Leverette, 2009)

\section{CONCLUSION}

The aim of the current research was to find the association between sleep schedules, mood and college performance of undergraduate students in the online education system during lockdown. With help of an online survey, data was collected from 130 students and significantly positive correlations were found between our three variables. The correlation coefficient between sleep and mood as well as sleep and college performance was found to be moderately positive whereas the correlation coefficient between mood and college performance of undergraduate students was found to be highly positive correlation. However, there remains a drawback of this current study, which is that these correlations do not imply causation, meaning that we cannot be sure as to what remains the exact causes to particular variables and/or are there any outside causes to these. Thus, this also leaves further scope of research in this dimension and correlation between these three variables.

\section{REFERENCES}

Becker, C. M., Adams, T., Orr, C., \& Quilter, L. (2008). Correlates of quality sleep and academic performance. Health Educator, 40(2), 82-89.

Browning, M. H., Larson, L. R., Sharaievska, I., Rigolon, A., McAnirlin, O., Mullenbach, L., et al., (2021). Psychological impacts from COVID-19 among university students: Risk factors across seven states in the United States. PloS one, 16(1), e0245327.

Cao, W., Fang, Z., Hou, G., Han, M., Xu, X., Dong, J., \& Zheng, J. (2020). The psychological impact of the COVID-19 epidemic on college students in China. Psychiatry research, 287, 112934.

Chiang, Y. C., Arendt, S., Zheng, T., \& Hanisch, K. (2014). The effects of sleep on academic performance and job performance. College Student Journal, 48(1), 72-87. 


\section{Correlates Between Sleep Schedules, Mood and College Performance of Students in Online Education During Lockdown}

Dellagiulia, A., Lionetti, F., Fasolo, M., Verderame, C., Sperati, A., \& Alessandri, G. (2020). Early impact of COVID-19 lockdown on children's sleep: a 4-week longitudinal study. Journal of Clinical Sleep Medicine, 16(9), 1639-1640.

DeRoma, V. M., Leach, J. B., \& Leverett, J. P. (2009). The relationship between depression and college academic performance. College Student Journal, 43(2), 325-335.

Etikan, I., \& Bala, K. (2017). Sampling and sampling methods. Biometrics \& Biostatistics International Journal, 5(6), 00149.

Gismero-González, E., Bermejo-Toro, L., Cagigal, V., Roldán, A., Martínez-Beltrán, M. J., \& Halty, L. (2020). Emotional impact of COVID-19 lockdown among the Spanish population. Frontiers in Psychology, 11.

Kroese FM, De Ridder DT, Evers C, Adriaanse MA. Bedtime procrastination: introducing a new area of procrastination. Front Psychol. 2014; 5:611. doi:10.3389/fpsyg.2014.00611

Marelli, S., Castelnuovo, A., Somma, A. et al. Impact of COVID-19 lockdown on sleep quality in university students and administration staff. J Neurol 268, 8-15 (2021). https://doi.org/10.1007/s00415-020-10056-6

Singh, R., Sharma, R., Suri, J. C., \& Das, S. (2009). Impact of sleep patterns on mood and academic performance of medical students. Indian Journal of Sleep Medicine (IJSM), 4(2).

\section{Acknowledgement}

The author(s) appreciates all those who participated in the study and helped to facilitate the research process.

\section{Conflict of Interest}

The author(s) declared no conflict of interest.

How to cite this article: Pundhir T. (2021). Correlates Between Sleep Schedules, Mood and College Performance of Students in Online Education During Lockdown. International Journal of Indian Psychology, 9(3), 2211-2215. DIP:18.01.210.20210903, DOI:10.25215/0903.210 